\title{
Mortality rate after open Roux-in-Y gastric bypass: a 10-year follow-up
}

\author{
S.M. Bruschi Kelles ${ }^{1,2,3}$, M.F.H.S. Diniz ${ }^{1}$, C.J. Machado ${ }^{1}$ and S.M. Barreto ${ }^{1}$ \\ ${ }^{1}$ Centro de Pós Graduação, Faculdade de Medicina, Universidade Federal de Minas Gerais, Belo Horizonte, MG, Brasil \\ ${ }^{2}$ Grupo de Avaliação de Tecnologias em Saúde, UNIMED, Belo Horizonte, MG, Brasil \\ ${ }^{3}$ Núcleo de Avaliação de Tecnologias em Saúde, Hospital das Clínicas, Universidade Federal de Minas Gerais, \\ Belo Horizonte, MG, Brasil
}

\begin{abstract}
The prevalence of obesity has increased to epidemic status worldwide. Thousands of morbidly obese individuals undergo bariatric surgery for sustained weight loss; however, mid- and long-term outcomes of this surgery are still uncertain. Our objective was to estimate the 10-year mortality rate, and determine risk factors associated with death in young morbidly obese adults who underwent bariatric surgery. All patients who underwent open Roux-in-Y gastric bypass surgery between 2001 and 2010 , covered by an insurance company, were analyzed to determine possible associations between risk factors present at the time of surgery and deaths related and unrelated to the surgery. Among the 4344 patients included in the study, $79 \%$ were female with a median age of 34.9 years and median body mass index (BMI) of $42 \mathrm{~kg} / \mathrm{m}^{2}$. The 30 -day and 10 -year mortality rates were 0.55 and $3.34 \%$, respectively, and $53.7 \%$ of deaths were related to early or late complications following bariatric surgery. Among these, $42.7 \%$ of the deaths were due to sepsis and $24.3 \%$ to cardiovascular complications. Male gender, age $\geq 50$ years, BMI $\geq 50 \mathrm{~kg} / \mathrm{m}^{2}$, and hypertension significantly increased the hazard for all deaths $(P<0.001)$. Age $\geq 50$ years, $\mathrm{BMI} \geq 50 \mathrm{~kg} / \mathrm{m}^{2}$, and surgeon inexperience elevated the hazard of death from causes related to surgery. Male gender and age $\geq 50$ years were the factors associated with increased mortality from death not related to surgery. The overall risk of death after bariatric surgery was quite low, and half of the deaths were related to the surgery. Older patients and superobese patients were at greater risk of surgery-related deaths, as were patients operated on by less experienced surgeons.
\end{abstract}

Key words: Survival analysis; Mortality; Follow-up studies; Morbid obesity; Roux-in-Y gastric bypass; Surgeon expertise

\section{Introduction}

The prevalence of obesity in many developed countries has reached the status of a global public health problem. In Brazil, $12.5 \%$ of men and $16.9 \%$ of women are affected by obesity. Obesity currently affects at least 18.5 million Brazilian individuals over 20 years of age, and morbid obesity, i.e., those whose body mass index (BMI) is equal to or above $40 \mathrm{~kg} / \mathrm{m}^{2}$, affects $0.8 \%$ of the population, which represents approximately one million persons. In the last 5 years, there was an increase of $70 \%$ in the number of morbidly obese individuals in Brazil. The distribution of this condition by gender is $0.4 \%$ for men and $1.1 \%$ for women (1).

Obese and extremely obese individuals are more prone to comorbidities, a lower quality of life, and shorter life expectancy compared to normal-weight individuals (2). Bariatric surgery has been shown to be more beneficial in terms of reduction of morbidity and weight loss compared with more conservative approaches $(3,4)$. Currently, it is well known that superobesity (BMI $\geq 50 \mathrm{~kg} / \mathrm{m}^{2}$ ), hypertension, diabetes mellitus, older age, and male gender are associated with an increased short-term mortality and adverse outcomes after bariatric surgery (5-12); however, the influence of these factors on long-term mortality is still uncertain.

Information on the results of bariatric surgery in the long term is scarce. The aim of the present study was to assess the 10-year mortality rate of morbidly obese patients in a Brazilian private health maintenance organization (HMO), as well as its associated factors.

\section{Material and Methods}

This nonconcurrent prospective cohort study included all morbidly obese patients who underwent bariatric surgery under the care of a private $\mathrm{HMO}$ in the city of Belo Horizonte, MG, Brazil, from January 2001 to December 
2010. Individuals under the age of 18 years and those with more than one bariatric procedure were excluded from the analysis. The Research Ethics Committee of Universidade Federal de Minas Gerais (COEP UFMG ETIC \#0074.0. 203.000-11) and the Ethics Committee of the $\mathrm{HMO}$ approved the study.

Candidates for bariatric surgery fulfilled the following criteria, established by the United States National Institutes of Health: BMI $\geq 40$ or BMI $\geq 35 \mathrm{~kg} / \mathrm{m}^{2}$ and comorbid conditions, such as hypertension, diabetes, sleep apnea, or severe arthropathy (13). Our preoperative investigation protocol included age, gender, BMI, a detailed medical history containing the list of comorbidities provided by the reference physician, and a psychological assessment by a psychiatrist who attested that the patient was psychologically stable enough to undergo surgery. Twelve patients were excluded from the analysis because they underwent bariatric surgery twice during the follow-up period.

Before surgery, a medical audit identified and notified the presence of the following comordibities: hypertension, diabetes mellitus, obstructive sleep apnea, and arthropathy. Hypertension was deemed to be present if the patients were taking anti-hypertensive medication or had blood pressure levels $\geq 140 / 90 \mathrm{mmHg}$ at the time of audit (14). Diabetes mellitus was defined as a medical diagnosis and/or the use of oral anti-diabetic medication and/or insulin (15). The presence of sleep apnea was identified by a formal diagnosis prior to the time of audit or the finding of an altered polysonnography (16). Arthropathy was judged present if formally diagnosed or by the presence of a related alteration in an image scan. All surgeries were performed as open Roux-in-Y gastric bypass.

Vital status and causes of death during the follow-up period were ascertained by means of a probabilistic record linkage using the Brazilian National Information System on Mortality (SIM). SIM has a very high coverage (almost 100\%) of the deaths occurring in the South and Southeast regions of Brazil, where our study was located $(17,18)$. Record linkage consisted of a three-stage process - one deterministic and two probabilistic (19) to obtain the corresponding death record and the official cause of death according to the International Classification of Diseases code (ICD-10 version). After identification, the causes of death were then grouped into 1) related or unrelated to the surgical procedure, and 2) being from natural causes or violence (external causes). Violent deaths included deaths from accidents, poisoning, suicides, and assault, and all the other deaths were regarded as being from natural causes. The inclusion of death in each of these categories was adjudicated independently by two of the authors (SMBK and MFHSD); when there was disagreement, a third coauthor reviewed the case (SMB).

The surgeon's expertise was determined from the number of surgeries performed per year by each surgeon ( $<20$ or $\geq 20$ bariatric surgeries). This cut-off was chosen based on the findings by Flum and Dellinger (8) of an increased mortality risk in patients operated by surgeons who had performed less than 20 procedures in their lifetime.

\section{Statistical analysis}

Descriptive analysis and the Pearson chi-squared test were used to verify the association between categorical variables. The normality of the distribution of continuous variables was verified by drawing a histogram and plots (Supplementary material). If the variables showed no indication of a normal distribution, median and interquartile ranges are reported rather than mean and standard deviation. The Mann-Whitney two-sample rank sum test was used for differences between medians. The Levene test assessed the equality in variance of these variables. Percentage distributions of each of the different causes of death in the overall number of deaths were computed.

Data were set for survival analysis with vital status as the failure variable. The time variable was the difference in years between entry (the date of bariatric surgery) and the end of follow-up or the date of death, if it occurred before the end of the study. Median and interquartile ranges of survival time after surgery are reported for all deaths and according to the category of the death (related or unrelated to surgery and from natural causes or violence).

Kaplan-Meier survival probability curves are reported for each gender and according to selected patient characteristics: age group ( $<50$ vs $\geq 50$ years) and BMI $\left(<50\right.$ vs $\geq 50 \mathrm{~kg} / \mathrm{m}^{2}$ ). Statistical differences between survival curves were analyzed by the log-rank test. Because there was no evidence that gender modified the effect of age and BMI on survival after bariatric surgery, the regression analysis was not stratified by gender.

A parametric model (the Weibull distribution) was used (20) to assess the factors statistically associated with all-cause mortality and each category of cause of death specified and to estimate the hazard ratios and their $95 \%$ confidence intervals. The Weibull model was chosen over other parametric models because of its flexibility and ability to model hazard functions that are decreasing, increasing, or constant over time. All variables with a $P$ value $<0.20$ in the univariate analysis were considered a candidate for the multivariate analysis and remained in the final model if $P$ was $\leq 0.05$.

Epi Info 6.04 (USA) was used for the descriptive analysis, and Stata Statistical Software: (Release 12; USA) was used for the survival and Weibull regression analyses.

\section{Results}

A total of 4344 patients from January 1, 2001 to December 31, 2010 were included in the study. At surgery, patients presented a median age of 34.9 years 
(28.6 and 43.6 years as first and third quartiles, respectively). Among all patients, 3443 (79.3\%) were female, $1723(39.7 \%)$ were hypertensive, 529 (12.2\%) had diabetes, 603 (13.9\%) had arthropathy, and 277 $(6.4 \%)$ had sleep apnea. BMI ranged from 35 to $82 \mathrm{~kg} / \mathrm{m}^{2}$ (median of $42 \mathrm{~kg} / \mathrm{m}^{2}$ with 40 and $46 \mathrm{~kg} / \mathrm{m}^{2}$ as first and third quartiles), and 499 (11.5\%) were superobese (BMI $\geq 50 \mathrm{~kg} / \mathrm{m}^{2}$ ). Male and female patients differed significantly with regard to BMI, surgeon experience, and prevalence of hypertension, diabetes, arthropathy, and sleep apnea. There was no gender difference in the proportion of deaths from causes related to the surgery. The proportion of deaths not related to surgery and from all causes was greater among men (Table 1).

The duration of follow-up ranged from 1 month to 10 years, with a median of 4.1 years (mean $\pm S D, 4.07 \pm 0.04$ years). Considering all causes of death, there were 24 deaths $(0.55 \%)$ in the first 30 days after surgery and 82 deaths $(1.9 \%)$ during the entire observation period. The 10 -year rate of death was $3.3 \%$ based on 197 bariatric surgery patients who entered the study in 2001 and were followed up to 2010 (Table 2).

The surgeries were performed in 19 different hospitals, and $80 \%$ of the procedures occurred in four hospitals. Fiftynine surgeons performed the surgeries, with seven surgeons being responsible for $70 \%$ of the procedures. Those seven surgeons performed more than 20 surgeries per year. In total, 157 of 3443 female patients had at least one pregnancy after the bariatric surgery, with a mean time from surgery to delivery of 2.7 years.

In total, $69(84.1 \%)$ deaths occurred from natural causes (disease-related) and 13 deaths (15.9\%) due to violence (Table 3). Forty-five (54\%) deaths were classified as strictly related to surgery. Sepsis, either early or late onset, was the most frequent cause of death among all deaths from natural causes, and $23(28.0 \%)$ deaths were related to sepsis and occurred up to 60 days after the procedure. The second most frequent cause of death in the natural cause subgroup was cardiovascular disease, with a significant impact of thromboembolism. Seven of 13 patients had thromboembolism and died within 15 days of surgery. Five patients presented with late intestinal ischemia, 3 with bowel infarction, and 2 with late limb ischemia. The other cardiovascular-related deaths were distributed as follows: 5 patients died of myocardial infarction ( 3 of them in the first 60 days after the procedure), 1 died after heart valve surgery, and 1 due to hepatic thrombosis.

Cancer was a relevant cause of death in the diseaserelated subgroup, with seven occurrences as follows: pancreatic cancer (2); cancers of the stomach (1), colon (1), neck (1), and ovaries (1); and multiple myeloma (1). Two women died during pregnancy. One presented severe malnutrition, demanding parenteral nutrition, and died after a pre-term cesarean section, 30 months after bariatric surgery. The second died after a laparoscopic procedure to treat intestinal occlusion, at 36 weeks of pregnancy, 6 years after bariatric surgery. In the subgroup of violent causes, suicide was the main cause of death (Table 3).

Table 3 shows the median and interquartile range of survival time from the date of surgery (entry to study) to the end of the study or the date of death, whichever occurred first. Most deaths related to surgery occurred in

Table 1. Characteristics of the cohort of patients who underwent bariatric surgery from 2001 to 2010 .

\begin{tabular}{|c|c|c|c|c|}
\hline Characteristics & Total $(n=4344)$ & Women $(n=3443)$ & Men $(n=901)$ & $\mathrm{P}^{*}$ \\
\hline \multicolumn{5}{|l|}{ Age (years) } \\
\hline Mean \pm SD & $36.6 \pm 10.5$ & $36.9 \pm 10.5$ & $36.2 \pm 10.5$ & $0.980^{\circ}$ \\
\hline Median (IQR) & $34.9(28.6-43.6)$ & $35.0(28.7-43.6)$ & $34.4(28.3-43.5)$ & $0.442^{\mathrm{b}}$ \\
\hline \multicolumn{5}{|l|}{ BMI $\left(\mathrm{kg} / \mathrm{m}^{2}\right)$} \\
\hline Mean \pm SD & $43.3 \pm 5.1$ & $42.8 \pm 4.8$ & $45.3 \pm 5.1$ & $<0.001^{a}$ \\
\hline Median (IQR) & $42(40-46)$ & $42(40-45)$ & $44(41-48)$ & $<0.001^{2}$ \\
\hline Age $\geq 50$ years & $573(13.2)$ & $467(13.6)$ & $106(11.8)$ & $0.155^{\mathrm{c}}$ \\
\hline $\mathrm{BMI} \geq 50 \mathrm{~kg} / \mathrm{m}^{2}$ & $499(11.5)$ & $318(9.2)$ & $181(20.1)$ & $<0.001^{\circ}$ \\
\hline Hypertension & $1723(39.7)$ & $1285(37.3)$ & $438(48.6)$ & $<0.001^{\mathrm{C}}$ \\
\hline Diabetes & $529(12.2)$ & $392(11.3)$ & $137(15.2)$ & $<0.002^{\circ}$ \\
\hline Arthropathy & $603(13.9)$ & $524(15.2)$ & $79(8.8)$ & $<0.001^{\circ}$ \\
\hline Sleep apnea & $277(6.4)$ & $185(5.4)$ & $92(10.2)$ & $<0.001^{\circ}$ \\
\hline$<20$ surgery/year & $1330(30.6)$ & $1082(31.4)$ & $248(27.5)$ & $0.024^{\circ}$ \\
\hline Death related to surgery & $44(1.0)$ & $31(0.9)$ & $13(1.4)$ & $0.148^{\circ}$ \\
\hline Death not related to surgery & $38(0.9)$ & $20(0.6)$ & $18(2.0)$ & $<0.001^{\circ}$ \\
\hline All causes of death & $82(1.9)$ & $51(1.5)$ & $31(3.4)$ & $<0.001^{\circ}$ \\
\hline
\end{tabular}

Data are reported as number with percent in parentheses unless otherwise indicated. IQR: interquartile range (25 and $75 \%)$; BMI: body mass index. * Men vs women; ${ }^{a}$ Levene test; ${ }^{\mathrm{b}}$ Mann-Whitney test; ${ }^{\mathrm{c}}$ Pearson chi-squared test (2-sided). 
Table 2. Survival rates after bariatric surgery during the 10-year follow-up according to cause of death.

\begin{tabular}{|c|c|c|c|c|c|c|c|}
\hline \multirow[t]{2}{*}{ Interval (years) } & \multirow[t]{2}{*}{ Patients (n) } & \multicolumn{2}{|c|}{ All causes of death $(n=82)$} & \multicolumn{2}{|c|}{$\begin{array}{c}\text { Cause of death related to } \\
\text { surgery }(n=44)\end{array}$} & \multicolumn{2}{|c|}{$\begin{array}{c}\text { Cause of death not related } \\
\text { to surgery }(n=38)\end{array}$} \\
\hline & & Deaths (n) & Survival & Deaths (n) & Survival & Deaths (n) & Survival \\
\hline 0 to $\leq 1$ & 4344 & 45 & 0.989 & 36 & 0.991 & 9 & 0.998 \\
\hline$>1$ to $\leq 2$ & 3961 & 10 & 0.967 & 3 & 0.991 & 7 & 0.996 \\
\hline$>2$ to $\leq 3$ & 3368 & 5 & 0.985 & 2 & 0.990 & 3 & 0.995 \\
\hline$>3$ to $\leq 4$ & 2837 & 4 & 0.983 & 0 & 0.990 & 4 & 0.993 \\
\hline$>4$ to $\leq 5$ & 2313 & 6 & 0.981 & 2 & 0.989 & 4 & 0.992 \\
\hline$>5$ to $\leq 6$ & 1904 & 3 & 0.979 & 0 & 0.989 & 3 & 0.990 \\
\hline$>6$ to $\leq 7$ & 1422 & 4 & 0.976 & 1 & 0.988 & 3 & 0.987 \\
\hline$>7$ to $\leq 8$ & 1068 & 3 & 0.972 & 0 & 0.988 & 3 & 0.984 \\
\hline$>8$ to $\leq 9$ & 511 & 2 & 0.967 & 0 & 0.988 & 2 & 0.978 \\
\hline$>9$ to $\leq 10$ & 200 & 0 & 0.967 & 0 & 0.988 & 0 & 0.978 \\
\hline$>10$ to $\leq 11$ & 85 & 0 & 0.967 & 0 & 0.988 & 0 & 0.978 \\
\hline
\end{tabular}

the first year of follow-up, and no death occurred after 7 years of observation.

Figure 1 shows the Kaplan-Meier survival curves for deaths related and not related to surgery according to age and BMI groups for men and women. Survival curves for deaths related to surgery (Figure $1 A$ and $B$ ) differed significantly according to age and BMI groups, both in men and women, while the survival curves for deaths not related to surgery only differed by age group in both genders (Figure 1C and D).

In the univariate analysis, age greater than 50 years and $\mathrm{BMI} \geq 50 \mathrm{~kg} / \mathrm{m}^{2}$ at surgery increased the hazard ratio of death from all causes, while hypertension and diabetes increased the risk of death only among women. When considering only the deaths related to surgery, BMI $\geq 50 \mathrm{~kg} / \mathrm{m}^{2}$ was associated with a higher hazard ratio. Age greater than 50 years and hypertension were associated with increased mortality from death not related to the bariatric surgery (Table 4).
Table 5 shows the results of the multivariate analysis for all causes of death, and death related or not related to surgery. Male gender, age $\geq 50$ years, BMI $\geq 50 \mathrm{~kg} / \mathrm{m}^{2}$, and hypertension remained significantly associated with increased mortality from all causes. Age $\geq 50$ years, BMl $\geq 50 \mathrm{~kg} / \mathrm{m}^{2}$, and low experience of the surgeon elevated the hazard of death from causes related to surgery. Male gender and age $\geq 50$ years were the only factors associated with increased mortality from death not related to surgery.

\section{Discussion}

In the present study, the 30-day mortality rate was $0.55 \%$, and the 10 -year mortality rate was $3.34 \%$. Considering the entire period of study, mortality from causes related to surgery was $1.0 \%$ and from violent death was $0.3 \%$. Early mortality rate was similar to that observed in other studies of patients who underwent the

Table 3. Causes of death during the 10-year follow-up and median and interquartile range of survival time after bariatric surgery, 2001-2010.

\begin{tabular}{lccc}
\hline Cause of death & Number (\%) & Median (months) & Interquartile range (months) \\
\hline Mortality related to surgery & $44(53.7)$ & 0.6 & $0.3-8.2$ \\
Mortality not related to surgery & $38(46.3)$ & 33.8 & $12.6-62.5$ \\
Death from natural causes & $69(84.1)$ & 4.7 & $0.4-33.3$ \\
Sepsis & $35(42.7)$ & 0.8 & $0.4-11.1$ \\
Cardiovascular condition & $20(24.3)$ & 8.3 & $0.5-43.6$ \\
$\quad$ Thromboembolism & $13(15.9)$ & 8.4 & $0.5-44.5$ \\
$\quad$ Other cardiovascular conditions & $7(8.5)$ & 8.2 & $1.0-29.4$ \\
Cancer & $7(8.5)$ & 57.2 & $39.9-58.0$ \\
Other non-cardiovascular conditions & $7(8.5)$ & 19.2 & $4.9-69.3$ \\
Violent deaths & $13(15.9)$ & 26.5 & $17.7-67.7$ \\
Suicide & $8(9.8)$ & 57.6 & $20.3-71.1$ \\
Accident/assault & $5(6.1)$ & 20.0 & $17.7-26.5$ \\
\hline
\end{tabular}



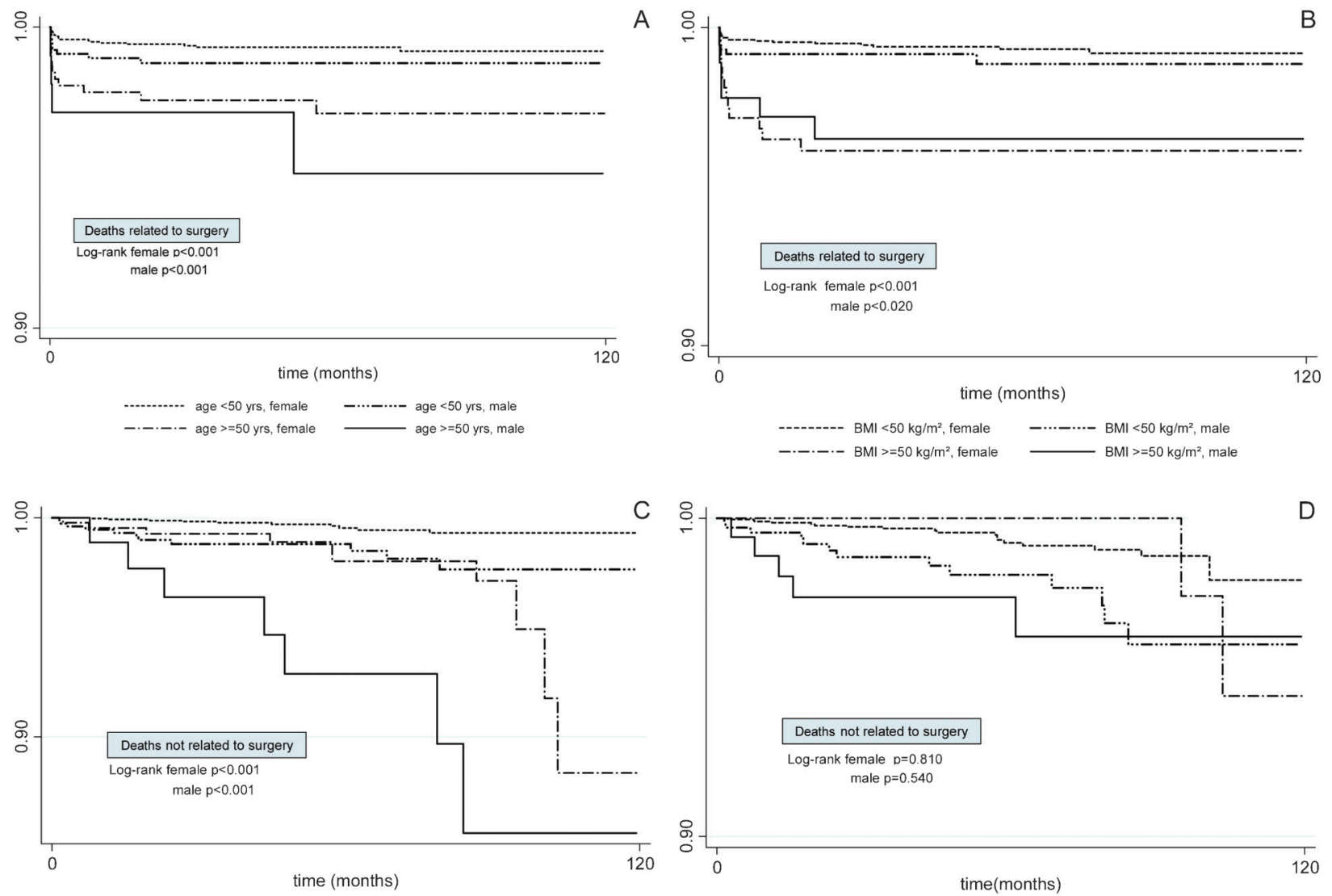

-...-.-. age $<50 \mathrm{yrs}$, female $\quad-\cdots-\cdots-$ age $<50 \mathrm{yrs}$, male
-.-.-.- age $>=50 \mathrm{yrs}$, female $\quad \longrightarrow$ age $>=50 \mathrm{yrs}$, male

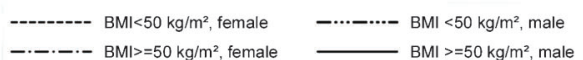

Figure 1. Gender specific Kaplan-Meier survival curves according to group for age and BMI, for deaths related $(A$ and $B)$ and not related to surgery $(C$ and $D)$.

same surgical procedure (21-23). Some studies reported higher mortality rates such as $0.9 \%(5), 1.9 \%(8), 3.7 \%$ (11), and $4.1 \%(12)$, but they included patients operated on much earlier, from 1980 to the early 2000s, when surgical conditions were probably less developed than today $(5,8)$. Flum and Dellinger (8) attributed their findings

Table 4. Results of the univariate analysis of factors associated with deaths from all causes as well as with death related and not related to surgery in a cohort of 4344 bariatric patients, 2001-2010.

\begin{tabular}{|c|c|c|c|c|c|c|c|c|c|}
\hline \multirow[t]{2}{*}{ Factors } & \multicolumn{3}{|c|}{$\begin{array}{l}\text { All causes of death } \\
\qquad(n=82)\end{array}$} & \multicolumn{3}{|c|}{$\begin{array}{l}\text { Mortality related to surgery } \\
\qquad(\mathrm{n}=44)\end{array}$} & \multicolumn{3}{|c|}{$\begin{array}{l}\text { Mortality not related to } \\
\text { surgery }(n=38)\end{array}$} \\
\hline & $\mathrm{HR}$ & $95 \% \mathrm{Cl}$ & $\mathrm{P}$ & $\mathrm{HR}$ & $95 \% \mathrm{Cl}$ & $P$ & $\mathrm{HR}$ & $95 \% \mathrm{Cl}$ & $P$ \\
\hline Male gender & 2.35 & $1.50-3.67$ & $<0.01$ & 1.62 & $0.84-3.09$ & 0.16 & 3.43 & $1.81-6.48$ & $<0.01$ \\
\hline Age $\geq 50$ years & 4.28 & $2.75-6.65$ & $<0.01$ & 3.68 & $1.99-6.80$ & $<0.01$ & 4.87 & $2.57-9.24$ & $<0.01$ \\
\hline $\mathrm{BMI} \geq 50 \mathrm{~kg} / \mathrm{m}^{2}$ & 3.19 & $1.99-5.10$ & $<0.01$ & 5.14 & $2.82-9.38$ & $<0.01$ & 1.51 & $0.67-3.43$ & 0.34 \\
\hline Hypertension & 2.76 & $1.76-4.35$ & $<0.01$ & 2.41 & $1.31-4.42$ & $<0.01$ & 3.20 & $1.62-6.35$ & $<0.01$ \\
\hline Diabetes & 1.51 & $0.85-2.69$ & 0.18 & 1.16 & $0.49-2.73$ & 0.74 & 1.92 & $0.88-4.21$ & 0.12 \\
\hline Sleep apnea & 1.14 & $0.53-2.48$ & 0.74 & 1.30 & $0.47-3.64$ & 0.63 & 0.86 & $0.26-2.81$. & 0.80 \\
\hline Arthropathy & 0.83 & $0.46-1.56$ & 0.58 & 0.84 & $0.35-1.99$ & 0.68 & 0.70 & $0.30-1.75$ & 0.47 \\
\hline Surgeon $\leq 20$ procedures/year & 1.20 & $0.76-1.91$ & 0.43 & 2.19 & $1.21-3.96$ & 0.01 & & & \\
\hline Year of surgery (baseline 2001) & 0.92 & $0.84-1.01$ & 0.08 & 0.97 & 0.86-1.09 & 0.59 & & & \\
\hline
\end{tabular}

HR: hazard ratio; 95\% Cl: 95\% confidence interval; BMI: body mass index. 
Table 5. Factors associated with deaths from all causes as well as deaths related and not related to surgery in the multivariate regression (Weibull) analysis of a cohort of 4344 bariatric patients, 2001-2010.

\begin{tabular}{|c|c|c|c|}
\hline Factors & Adjusted HR & $95 \% \mathrm{Cl}$ & $\mathrm{P}$ \\
\hline \multicolumn{4}{|l|}{ Overall mortality $(n=82)$} \\
\hline Male gender & 2.11 & $1.34-3.33$ & 0.001 \\
\hline Age $\geq 50$ years & 3.44 & $2.14-5.52$ & $<0.001$ \\
\hline $\mathrm{BMI} \geq 50 \mathrm{~kg} / \mathrm{m}^{2}$ & 2.39 & $1.47-3.86$ & $<0.001$ \\
\hline Hypertension & 1.73 & $1.06-2.81$ & 0.027 \\
\hline \multicolumn{4}{|l|}{ Related to surgery } \\
\hline Age $\geq 50$ years & 3.16 & $1.70-5.85$ & $<0.001$ \\
\hline $\mathrm{BMI} \geq 50 \mathrm{~kg} / \mathrm{m}^{2}$ & 4.90 & $2.68-8.97$ & $<0.001$ \\
\hline Surgeon $\leq 20$ procedures/year & 2.18 & $1.20-3.94$ & 0.010 \\
\hline \multicolumn{4}{|l|}{ Not related to surgery } \\
\hline Male gender & 5.22 & $1.96-7.01$ & $<0.001$ \\
\hline Age $\geq 50$ years & 3.71 & $2.75-9.90$ & $<0.001$ \\
\hline
\end{tabular}

HR: hazard ratio; 95\% $\mathrm{Cl}$ : 95\% confidence interval; BMI: body mass index.

of higher mortality rates to lower surgical experience. However, compared with our cohort, studies involving predominantly laparoscopic procedures presented lower mortality rates, such as $0.2 \%(7), 0.3 \%(24)$, and $0.4 \%(25)$.

For this study, the 10-year mortality rate was lower than the rate found in large population-based cohorts, but those included several other surgical techniques $(3,7,8,26)$. The present cohort, with a mean patient age of $36.2 \pm 10.5$ years, represents the youngest population ever studied $(3,5,8$, $9,25,27)$, as well one with the lowest mean BMI $\left(43.3 \mathrm{~kg} / \mathrm{m}^{2}\right)$ reported $(5,8,25,27)$, only behind the cohorts of Sjöström et al. (3) and Adams et al. (9). These characteristics may explain, at least in part, our findings of low mortality rate.

Higher preoperative BMI remained a predictor for overall death and for deaths related to surgery. KaplanMeier curves show that BMI above $50 \mathrm{~kg} / \mathrm{m}^{2}$ is associated with early death after bariatric procedure. Sjöström et al. (3) did not find any significant association between the BMI subgroup and mortality, but their cut-off point was $40.8 \mathrm{~kg} / \mathrm{m}^{2}$. Arteburn et al. (26) also found a significantly increased risk of death among superobese patients $\left(\geq 50 \mathrm{~kg} / \mathrm{m}^{2}\right)$.

Overall, just over half of the deaths were related to the surgery. Anastomotic leak associated with sepsis was the first and thromboembolism was the second cause of early deaths. In the present study, the frequency of sepsis was higher and the frequency of thromboembolism was lower compared to the results of other authors $(5,7,25)$. In most studies, the percentages of death due to infection and thromboembolism vary from 7 to $18 \%$ and from 4 to $38 \%$, respectively $(5,7,22,26)$. The lower frequency of deaths from thromboembolism may be explained by the younger age and lower BMI of the patients in our cohort.

The surgeon's low experience, defined as less than 20 surgeries per year, was associated with an increase in mortality from causes related to surgery. The role of the surgeon's experience in the outcome of bariatric surgery has been previously addressed. (8,22,28-30). However, different cut-off points were used to define surgeon low experience, ranging from 15 to 50 procedures/year $(29,30)$. Nevertheless, results were all consistent regarding the lower mortality rates of patients operated on by more experienced surgeons.

Male gender has been associated with lower survival rates after bariatric procedure in several studies $(6,7,21)$, when analyzing all causes of death. This may be explained by factors not related to the bariatric surgery itself. Men generally have a higher overall risk of death than women, mostly due to violence and other genderrelated factors, such as drinking, smoking, and other behaviors (31-33). Thus, the finding of no association between male gender and mortality related to surgery seems reasonable and in accordance with the findings from most long-term follow-up studies $(3,8,9,22,26,34)$.

In the present cohort, 157 women became pregnant after bariatric surgery. Two of them died, one due to intestinal obstruction and the other to severe malnutrition. This result represents more than 50 times the maternal mortality rate compared to the general population (35). Because of the low numbers, it is not possible to test whether the risk of these complications is elevated following bariatric surgery. Mothers with prior bariatric surgery, regardless of obesity status, are more likely to have anemia, chronic hypertension, endocrine disorders, and small for gestational age infants (36). While there are many potential benefits of bariatric surgery for women considering future pregnancy, there might also be some risks, and support from a multidisciplinary team during pregnancy is evident (37). Based on 13 case reports, Maggard et al. (37) found 14 complications requiring surgical intervention such as small bowel obstructions due to internal hernia, mid-gut volvulus (1 from adhesions), 
perforated gastric ulcer, band complications (including erosion and bleeding), and staple line stricture. Eight of these bariatric procedures were performed laparoscopically and six were performed in an open fashion. There were three maternal deaths (21.4\%) (38).

Suicides comprised $10 \%$ of all deaths in our cohort, which suggests that the preoperation protocol may require improvement to capture tendencies for alcoholism and self-harm behavior. The association between obesity and fatal and nonfatal suicide is controversial (39), but it appears that bariatric surgery patients are at increased risk of suicide (40). Heneghan et al. (40) found an increased risk of suicide among obese individuals, which persisted after bariatric surgery intervention. Although our study does not show an association between bariatric surgery and suicidal behavior, given the lack of a control group, our results suggest that further research is warranted to find the optimal approach to evaluate candidates for surgery, including extensive psychological preprocedure evaluation and long-term follow-up.

This nonconcurrent cohort has strengths and weaknesses. It is based on registry data that were not generated specifically for a research purpose. Nevertheless, the study took advantage of a wellstructured database that included administrative data. Additionally, there were audits performed by the same surgeon for every candidate for bariatric surgery. Although the audit was not intended to be part of the research, data collected by the same surgeon provides data consistency. We assumed that all individuals were alive at the end of the study if they were not found in the Mortality System database.

Compared to other studies, the patients in our cohort were younger and had a lower BMI. This may be due to the easy access to surgical procedures experienced by these patients once they are covered by a private healthcare

\section{References}

1. Brasil, Ministério da Saúde, Ministério do Planejamento, Orçamento e Gestão. Pesquisa de orçamentos familiares 2008-2009: antropometria e estado nutricional de crianças, adolescentes e adultos no Brasil. Brasília: IBGE; 2009. www.ibge.gov.br/home/estatistica/populacao/condicaodevida/ pof/2008_2009_encaa/pof_20082009_encaa.pdf.

2. Fontaine $\mathrm{KR}$, Redden DT, Wang $\mathrm{C}$, Westfall $\mathrm{AO}$, Allison DB. Years of life lost due to obesity. JAMA 2003; 289: 187-193, doi: 10.1001/jama.289.2.187.

3. Sjostrom L, Narbro K, Sjostrom CD, Karason K, Larsson B, Wedel $\mathrm{H}$, et al. Effects of bariatric surgery on mortality in Swedish obese subjects. N Engl J Med 2007; 357: 741-752, doi: 10.1056/NEJMoa066254.

4. Pontiroli AE, Morabito A. Long-term prevention of mortality in morbid obesity through bariatric surgery. a systematic review and meta-analysis of trials performed with gastric banding and gastric bypass. Ann Surg 2011; 253: 484-487, doi: $10.1097 /$ SLA.0b013e31820d98cb. organization where there are no coverage-limiting restrictions. The external validity of the present findings may be limited to individuals covered by health plans and with access to the same hospitals included in this study, but the associations found are likely to represent true risk factors for mortality from causes related to bariatric surgery. This study represents the first long-term assessment of the outcomes of bariatric surgery in a large Brazilian cohort. Thousands of morbidly obese patients undergo bariatric surgery as the final attempt to lose weight. In these patients, death, up to 10 years after the procedure, is a rare event, but can be reduced further by improving surgeon experience and reducing the BMI of superobese patients before surgery. We did not confirm that male gender is a risk factor for long-term deaths related to bariatric surgery. The high suicide rate after the procedure suggests the need for improving the patient's pre- and postoperative psychological evaluation and follow-up control.

\section{Supplementary Material}

Click here to view [pdf].

\section{Acknowledgments}

The authors thank Dr. Renata Bertazzi Levy for the data on prevalence of morbid obesity in the Family Budget Survey, 2008 (not published). The authors wish to express our gratitude to the staff, especially to librarians Mrs. Mariza Cristina Torres Talim, Miss Mariana Fernandes Ribeiro, and Jamil Souza Nascimento for record linkage data from SIM. We wish to thank Dr. Fernando M. Biscione, Anderson Ribeiro Oliveira, and Ana Paula Franco Viegas Pereira for the database. Research supported by FAPEMIG (Projeto No. APQ02241-10).

5. Omalu BI, Ives DG, Buhari AM, Lindner JL, Schauer PR, Wecht $\mathrm{CH}$, et al. Death rates and causes of death after bariatric surgery for Pennsylvania residents, 1995 to 2004 Arch Surg 2007; 142: 923-928, doi: 10.1001/archsurg.142. 10.923.

6. Zhang W, Mason EE, Renquist KE, Zimmerman MB. Factors influencing survival following surgical treatment of obesity. Obes Surg 2005; 15: 43-50, doi: 10.1381/0960892 052993422.

7. Marsk R, Freedman J, Tynelius P, Rasmussen F, Naslund E. Antiobesity surgery in Sweden from 1980 to 2005: a population-based study with a focus on mortality. Ann Surg 2008; 248: 777-781, doi: 10.1097/SLA.0b013e318189b0cf.

8. Flum DR, Dellinger EP. Impact of gastric bypass operation on survival: a population-based analysis. J Am Coll Surg 2004; 199: 543-551, doi: 10.1016/j.jamcollsurg.2004.06.014.

9. Adams TD, Gress RE, Smith SC, Halverson RC, Simper $\mathrm{SC}$, Rosamond WD, et al. Long-term mortality after gastric 
bypass surgery. N Engl J Med 2007; 357: 753-761, doi: 10.1056/NEJMoa066603.

10. Marsk R, Naslund E, Freedman J, Tynelius P, Rasmussen $\mathrm{F}$. Bariatric surgery reduces mortality in Swedish men. $\mathrm{Br} \mathrm{J}$ Surg 2010; 97: 877-883, doi: 10.1002/bjs.6985.

11. Martins-Filho ED, Camara-Neto JB, Ferraz AA, Amorim M, Ferraz EM. Evaluation of risk factors in superobese patients submitted to conventional Fobi-Capella surgery. Arq Gastroenterol 2008; 45: 3-10, doi: 10.1590/S0004-2803200 8000100002.

12. Diniz MFHS, Passos VMA, Barreto SMB, Diniz MTC, Linares DB, Mendes LN. [The Public Health System Classe III obese patients' profile, who have undergone "ROUX-en-Y" gastroplasty, in the UFMG Hospital das Clinicas: superobesity, co-morbidity and hospital mortality high prevalence]. Rev Med Minas Gerais 2008; 18: 183190.

13. No authors listed. Gastrointestinal surgery for severe obesity. Proceedings of a National Institutes of Health Consensus Development Conference. March 25-27, 1991, Bethesda, MD. Am J Clin Nutr 1992; 55 (2 Suppl): 487S619 S.

14. Sociedade Brasileira de Cardiologia (SBC), Sociedade Brasileira de Hipertensão (SBH), Sociedade Brasileira de Nefrologia (SBN). [V Guidelines for ambulatory blood pressure monitoring (ABPM) and III Guidelines for home blood pressure monitoring (HBPM)]. Arq Bras Cardiol 2011; 97: 1-24.

15. American Diabetes Association. Standards of medical care in diabetes 2012. Diab Care 2012; 35 (Suppl 1): S11-S63.

16. Epstein LJ, Kristo D, Strollo PJ Jr, Friedman N, Malhotra A, Patil SP, et al. Clinical guideline for the evaluation, management and long-term care of obstructive sleep apnea in adults. J Clin Sleep Med 2009; 5: 263-276.

17. Rede Interagencial de Informação para a Saúde (RIPSA). Indicadores básicos para a saúde no Brasil: conceitos e aplicações. 2nd edn. Brasília: OPAS; 2008.

18. Schmidt MI, Duncan BB, Azevedo e Silva G, Menezes AM, Monteiro CA, Barreto SM, et al. Chronic non-communicable diseases in Brazil: burden and current challenges. Lancet 2011; 377: 1949-1961, doi: 10.1016/S0140-6736(11)601359.

19. Machado CJ, Hill K. Probabilistic record linkage and an automated procedure to minimize the undecided-matched pair problem. Cad Saude Publica 2004; 20: 915-925, doi: 10.1590/S0102-311X2004000400005.

20. Kirkwood BR, Sterne JAC. Essential medical statistics. 2nd edn. Oxford: Blackwell; 2003.

21. Santo MA, Pajecki D, Riccioppo D, Cleva R, Kawamoto F, Cecconello I. Early complications in bariatric surgery: incidence, diagnosis and treatment. Arq Gastroenterol 2013; 50: 50-55.

22. Hutter MM, Randall S, Khuri SF, Henderson WG, Abbott WM, Warshaw AL. Laparoscopic versus open gastric bypass for morbid obesity: a multicenter, prospective, riskadjusted analysis from the National Surgical Quality Improvement Program. Ann Surg 2006; 243: 657-662, doi: 10.1097/01.sla.0000216784.05951.0b.

23. Morino M, Toppino M, Forestieri $\mathrm{P}$, Angrisani L, Allaix ME, Scopinaro N. Mortality after bariatric surgery: analysis of 13,871 morbidly obese patients from a national registry. Ann
Surg 2007; 246: 1002-1007, doi: 10.1097/SLA.0b013e31815 c404e.

24. Longitudinal Assessment of Bariatric Surgery (LABS) Consortium, Flum DR, Belle SH, King WC, Wahed AS, Berk $P$, et al. Perioperative safety in the longitudinal assessment of bariatric surgery. N Engl J Med 2009; 361: 445-454, doi: 10.1056/NEJMoa0901836.

25. Nguyen NT, Silver M, Robinson M, Needleman B, Hartley $\mathrm{G}$, Cooney R, et al. Result of a national audit of bariatric surgery performed at academic centers: a 2004 University Health System Consortium Benchmarking Project. Arch Surg 2006; 141: 445-449, doi: 10.1001/archsurg.141.5.445.

26. Arterburn D, Livingston EH, Schifftner T, Kahwati LC, Henderson WG, Maciejewski ML. Predictors of long-term mortality after bariatric surgery performed in Veterans Affairs medical centers. Arch Surg 2009; 144: 914-920, doi: 10.1001/archsurg.2009.134.

27. Christou NV, Sampalis JS, Liberman M, Look D, Auger S, McLean AP, et al. Surgery decreases long-term mortality, morbidity, and health care use in morbidly obese patients. Ann Surg 2004; 240: 416-423, doi: 10.1097/01.sla.0000137343. 63376.19.

28. Kelles SM, Barreto SM, Guerra HL. Mortality and hospital stay after bariatric surgery in 2,167 patients: influence of the surgeon expertise. Obes Surg 2009; 19: 1228-1235, doi: 10.1007/s11695-009-9894-7.

29. Smith MD, Patterson E, Wahed AS, Belle SH, Bessler M, Courcoulas AP, et al. Relationship between surgeon volume and adverse outcomes after RYGB in Longitudinal Assessment of Bariatric Surgery (LABS) study. Surg Obes Relat Dis 2010; 6: 118-125, doi: 10.1016/j.soard.2009.09.009.

30. Chiu CC, Wang JJ, Tsai TC, Chu CC, Shi HY. The relationship between volume and outcome after bariatric surgery: a nationwide study in Taiwan. Obes Surg 2012; 22: 1008-1015, doi: 10.1007/s11695-012-0636-x.

31. Shield KD, Kehoe T, Taylor B, Patra J, Rehm J. Alcoholattributable burden of disease and injury in Canada, 2004. Int J Public Health 2012; 57: 391-401, doi: 10.1007/s00038011-0247-7.

32. Bauer T, Gohlmann S, Sinning M. Gender differences in smoking behavior. Health Econ 2007; 16: 895-909, doi: 10.1002/hec.1259.

33. Steljes TP, Fullerton-Gleason L, Kuhls D, Shires GT, Fildes $\mathrm{J}$. Epidemiology of suicide and the impact on Western trauma centers. J Trauma 2005; 58: 772-777, doi: 10.1097/ 01.TA. 0000158253.15597. .CE.

34. Livingston EH, Huerta S, Arthur D, Lee S, De Shields S, Heber D. Male gender is a predictor of morbidity and age a predictor of mortality for patients undergoing gastric bypass surgery. Ann Surg 2002; 236: 576-582, doi: 10.1097/ 00000658-200211000-00007.

35. Soares VM, de Souza KV, de Azevedo EM, Possebon CR, Marques FF. [Causes of maternal mortality according to levels of hospital complexity]. Rev Bras Ginecol Obstet 2012 34: 536-543, doi: 10.1590/S0100-72032012001200002.

36. Belogolovkin V, Salihu HM, Weldeselasse H, Biroscak BJ, August EM, Mbah AK, et al. Impact of prior bariatric surgery on maternal and fetal outcomes among obese and nonobese mothers. Arch Gynecol Obstet 2012; 285: 12111218, doi: 10.1007/s00404-011-2134-0.

37. Maggard M, Li Z, Yermilov I. Bariatric surgery in women of 
reproductive age: special concerns for pregnancy. Rockville (MD): Agency for Healthcare Research and Quality (US); 2008 Nov. (Evidence Reports/Technology Assessments, No. 169) Chapter 3, Results. http://www.ncbi.nlm.nih.gov/ books/NBK38568/.

38. Hezelgrave NL, Oteng-Ntim E. Pregnancy after bariatric surgery: a review. J Obes 2011; 2011: 501939, doi: 10.1155/ 2011/501939.
39. Tindle HA, Omalu B, Courcoulas A, Marcus M, Hammers J, Kuller LH. Risk of suicide after long-term follow-up from bariatric surgery. Am J Med 2010; 123: 1036-1042, doi: 10.1016/j.amjmed.2010.06.016.

40. Heneghan HM, Heinberg L, Windover A, Rogula T, Schauer PR. Weighing the evidence for an association between obesity and suicide risk. Surg Obes Relat Dis 2012; 8: 98107, doi: 10.1016/j.soard.2011.10.007. 